\title{
REVISTAMARACANAN
}

Artigo

\section{Interesses empresariais e a política de saneamento urbano durante a ditadura civil-militar brasileira (1964-1988): a construção da lógica dos grandes projetos e das grandes soluções}

\section{Business interests and urban sanitation policy during the Brazilian civil- military dictatorship (1964-1988): the construction of the logic of big projects and big solutions}

Pedro Henrique Campos* Universidade Federal Rural do Rio de Janeiro Rio de Janeiro, Rio de Janeiro, Brasil

Recebido em: 24 nov. 2020.

Aprovado em: 02 jun. 2021.

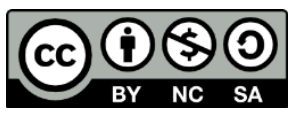

A pesquisa que deu origem a este artigo contou com o financiamento do CNPq e da Faperj.

* Professor do Departamento de História e Relações Internacionais (DHRI) da Universidade Federal Rural do Rio de Janeiro (UFRRJ), atuando no Programa de Pós-Graduação de História da UFRRJ (PPHR) e no Programa de Economia Política Internacional da UFRJ (Pepi). Mestre em História Social pela Universidade Federal Fluminense (UFF) e doutor em História pela mesma instituição. (phpcampos@yahoo.com.br) 


\title{
Resumo
}

O artigo analisa as políticas públicas para o setor do saneamento urbano durante a ditadura civilmilitar e sua relação com os interesses empresariais vigentes naquele período. Usando fontes corporativas, memórias e imprensa, o texto traz um histórico sobre o ramo no século $X X$, problematiza os interesses privados organizados no setor, aborda as políticas no período da ditadura e trata de alguns dos grandes programas para a área na época, como os emissários submarinos, o sistema de abastecimento da grande São Paulo e o projeto Nordestão. Nossa questão gira em torno do porquê da inclinação para as grandes soluções prevendo vultosas obras de engenharia e quem eram os setores e grupos favorecidos por essa escolha. Trabalhamos a hipótese de que durante a ditadura, dadas as particularidades do regime e seu conteúdo social, os interesses empresariais parecem ter tido um peso significativo para compreender as políticas endereçadas ao ramo do saneamento urbano.

Palavras-chave: Saneamento. Ditadura civil-militar brasileira. Interesses empresariais. Políticas públicas.

\begin{abstract}
The article analyzes public policies for the urban sanitation during the Brazilian civil-military dictatorship and the relationship with the business interests. Using corporative sources, memoirs and the press, the text brings a history of the sector in the 20th century, questions the private interests organized in the sector, addresses the policies during the dictatorship period and addresses some of the major programs for the area at the time, as the submarine outfalls, a supply system for the greater São Paulo, and the Nordestão project. Our question revolves around why the inclination towards big solutions foreseeing large engineering works and who were the sectors and groups favored by this choice. We work on the hypothesis that during the dictatorship, given the particularities of the regime and its social content, business interests seem to have had a significant weight in understanding the policies addressed to the field of urban sanitation.
\end{abstract}

Keywords: Sanitation. Brazilian civil-military dictatorship. Business interests. Public policy. 
O que eu acho que está acontecendo no Brasil é a falta de vontade política, porque infelizmente os nossos governantes querem investir em soluções que vão atender aos interesses políticos, soluções que dão voto.

Por exemplo, é muito melhor para o mau político construir uma grande barragem que arrebenta o rio, mas dá voto, tem muito dinheiro ali para conseguir empreiteiras, pagar etc., do que investir em reflorestamento, controle de erosão do solo, fazer trabalho de reuso e aproveitamento, soluções sustentáveis, baratas.

Adacto Ottoni

Em bom português, o que você está dizendo é que as soluções de baixo custo não interessam a certos grupos econômicos que oferecem serviços que são mais caros e que implicam em grandes obras.

André Trigueiro ${ }^{1}$

A grave crise hídrica que atingiu a região metropolitana do Rio de Janeiro no início do ano de 2020 evidenciou uma série de fragilidades nas políticas públicas de saneamento urbano para atender às cidades do grande Rio. Em meio aos debates ocorridos em torno da questão, a citação acima - fruto de um diálogo entre Adacto Ottoni, professor do Departamento de Engenharia Sanitária e Ambiental da Uerj, e o jornalista André Trigueiro - assinala um elemento importante que ajuda a entender o "fracasso" das políticas estatais, que diz respeito justamente aos interesses econômicos em torno das obras e serviços que podem ser prestados e geram oportunidades e lucros para algumas empresas, muitas vezes não exatamente condizentes com as demandas ou a necessidade da maior parte da população.

A captura das políticas públicas para o atendimento de certos interesses e não do bemestar de um conjunto mais amplo da sociedade não é exatamente um fenômeno novo na política brasileira. Pelo contrário, historicamente interesses empresariais têm conseguido pautar as políticas estatais conforme seus objetivos, não necessariamente afinados com o requerido por

\footnotetext{
1 GLOBONEWS. Programa Cidades e Soluções. Com André Trigueiro, Fabiano Thompson e Adacto Ottoni. Gravado e publicado em 21/01/2020. Disponível no endereço: https://www.youtube.com/watch?v=NiMJLuvA2Kc\&t=770s acessado em 21/02/2020.
} 
segmentos mais amplos da população, sobretudo os grupos sociais mais desfavorecidos. Particularmente essa lógica prevaleceu durante a ditadura civil-militar brasileira, inaugurada com o golpe de Estado de 1964, quando se deu um processo de restrição da participação política e do processo decisório, com a escalada dos interesses empresariais e militares na condução do Estado e das políticas públicas, em desfavor do conjunto mais amplo da sociedade e das classes subalternas em particular. Assim, foram montados grandes projetos que atendiam a interesses específicos, mas com ganhos duvidosos para a população como um todo. São conhecidos os casos de rodovias como a Transamazônica e grandes usinas hidrelétricas, de significativo impacto sócio-ambiental, como Itaipu e Tucuruí, que atendiam a interesses como os das empreiteiras responsáveis pelas obras civis e os consumidores eletro-intensivos, que tinham garantido o fornecimento de energia elétrica subsidiada, mas que não oferecia maiores ganhos para a maior parte da população, sendo na verdade um flagelo para os segmentos afetados por esses grandes projetos.

No setor das políticas públicas voltadas para o saneamento urbano deu-se uma lógica similar, com a montagem de um programa de ação estatal bastante audacioso e rebuscado, mas que privilegiava grandes intervenções de engenharia, com muitos impactos sobre a população e poucos benefícios para a mesma, além de significativas oportunidades de negócios e lucros para grupos empresariais ligados ao regime. Essas ações geram questões acerca de quem pautava as políticas públicas naquele contexto, tendo em vista a escolha dessas grandes soluções para o abastecimento de água e esgoto para as maiores cidades brasileiras. Dessa forma, pretendemos neste artigo analisar os interesses empresariais envolvidos com as políticas públicas para a área do saneamento urbano durante a ditadura, problematizando os beneficiários dessas ações e a aplicação de grandes projetos nas principais regiões urbanas do país. Nossa questão gira em torno do porquê da inclinação para as grandes soluções prevendo vultosas obras de engenharia e quem eram os setores e grupos favorecidos por essa escolha.

As fontes utilizadas neste texto foram produzidas no período, sendo compostas por documentos, testemunhos, publicações e memórias empresariais, combinados com material legal e derivado das políticas oficiais aplicadas naquele contexto. Com isso, entendemos que podemos tentar verificar os favorecidos pelas políticas públicas, visualizando o perfil classista do Estado e das ações estatais. Nossa orientação teórico-metodológica se respalda justamente na problematização da relação entre os interesses do empresariado e a ditadura civil-militar brasileira, tentando verificar o conteúdo social daquele regime e quem eram os setores da sociedade beneficiados pelas políticas públicas. Assim, nos postulamos no trabalho de Dreifuss, ${ }^{2}$ que conseguiu identificar e analisar especificamente para o golpe de 1964 o seu conteúdo de classe e a participação decisiva do empresariado internacional e associado ao capital estrangeiro no processo de derrubada do governo João Goulart, além da elaboração prévia de propostas de reformulação do Estado capitalista brasileiro e das políticas públicas, com diretrizes que, em boa

2 DREIFUSS, René Armand. 1964: a conquista do Estado; ação política, poder e golpe de classe. Petrópolis: Vozes, 1981. 
medida, vieram a ser postas em prática na forma de políticas públicas ao longo da ditadura, principalmente em seus anos iniciais. Hoje já existe uma farta produção acadêmica sobre a interface entre empresariado e ditadura no Brasil $^{3}$ que tem ajudado a avançar o conhecimento acerca dessa faceta civil da ditadura, problematizando os responsáveis pelo golpe e o regime, bem como os beneficiários das políticas estatais aplicadas naquele período. Tentamos com o presente texto justamente contribuir com essa agenda de trabalho.

Dessa forma, dividimos o texto em quatro partes principais. Após essas considerações iniciais, procedemos uma breve abordagem do histórico das políticas públicas de saneamento postas em prática no Brasil durante o século XX, em período anterior à ditadura. Logo depois, tratamos dos interesses empresariais envolvidos com as políticas públicas para o setor do saneamento urbano, enfatizando os grupos econômicos e organizações de classe dos empreiteiros de obras públicas. Em seguida, abordamos especificamente a ação estatal para o setor do saneamento urbano ao longo da ditadura civil-militar brasileira. Por fim, tratamos de alguns dos grandes projetos postos em prática naquele período, assinalando a importância dos interesses empresariais para a montagem e implementação de ações como a construção de emissários submarinos em várias cidades litorâneas brasileiras, o Sistema de Abastecimento de Águas e Esgotos da Grande São Paulo (Sanegran), bem como o projeto Nordestão, do período final da ditadura.

\section{Breve histórico acerca das políticas de saneamento urbano no Brasil}

O conceito de saneamento diz respeito a um conjunto de medidas que visa prevenir doenças e promover a saúde. Já o saneamento básico abrange o abastecimento de água, esgoto sanitário, drenagem, limpeza urbana e controle da poluição do ar, do solo e das águas. Durante o século XIX, com as grandes epidemias de cólera e a formação das grandes cidades - em meio ao processo de industrialização -, a questão ganhou força e passou a gerar uma série de ações estatais no sentido de impedir o alastramento de doenças e ordenar socialmente o espaço urbano. Em meados do século, uma série de invenções foram desenvolvidas, como o hidrante e os primeiros medidores de água. ${ }^{4}$ A crise social e da saúde em grandes cidades da Inglaterra, ${ }^{5}$ além de Londres e Paris ${ }^{6}$ foram retratados em obras e relatos do período e textos posteriores, e passou a ser modelo a intervenção urbana do barão de Haussmann na capital francesa, que tinha o objetivo de evitar a difusão de epidemias, ao mesmo tempo em que continha as classes subalternas e evitava levantes populares. ${ }^{7}$

\footnotetext{
3 CAMPOS, Pedro Henrique Pedreira. Empresariado e ditadura no Brasil: fontes, métodos e historiografia. Sillogés, v. 3, p. 15-42, 2020.

4 JORGE, Wilson Edson. A Política Nacional de Saneamento Pós-64. Tese de doutorado em Arquitetura e Urbanismo. São Paulo: USP, 1987.

5 ENGELS, Frederich. A Situação da Classe Trabalhadora na Inglaterra. São Paulo: Global, 1988 [1845].

${ }^{6}$ BRESCIANI, Maria Stella. Londres e Paris no Século XIX: o espetáculo da pobreza. São Paulo: Brasiliense, 1981.

7 BENCHIMOL, Jaime Larry. Pereira Passos: um Haussmann tropica; a renovação urbana da cidade do Rio de Janeiro no início do século XX. Rio de Janeiro: Secretaria Municipal de Cultura, 1992.
} 
No Brasil, a questão passou a ser tratada ainda no Império, com objetivo de repelir ou sanar as epidemias que assolavam o país no período. O porto era um local particular de demanda de ação do poder estatal, tendo em vista as denúncias de más condições sanitárias e trânsito de pessoas, doenças e infecções no local. ${ }^{8}$ Apesar de algumas ações episódicas para 0 abastecimento de água e esgotos durante o período colonial e o Império, as políticas públicas de fôlego mais intenso vieram a ser estabelecidas no período republicano. Em meio ao novo texto constitucional, foi formado em 1891 o Ministério da Indústria, Viação e Obras Públicas (MIVOP), pasta que sofreu alteração no final da primeira década do século $X X$, quando deixou de tratar da temática industrial, transferida para o recém-criado Ministério da Agricultura, Indústria e Comércio (MAIC). Dessa forma, o Ministério de Viação e Obras Públicas (MVOP) seria o responsável por assuntos relativos às estradas de ferro e de rodagem, navegação marítima, fluvial e aérea, exploração e navegabilidade de rios, desobstrução de canais e pontes, além das obras públicas federais nos estados e no Distrito Federal. Voltado mais para as áreas de viação e transportes, o ministério não dispunha de uma instância específica dedicada à temática do saneamento e não possuía atribuições claras a esse respeito. ${ }^{9}$

Foi só depois do golpe de 1930 que as primeiras políticas de maior fôlego em nível federal foram formadas para o ramo de saneamento. Um marco importante nas políticas para o setor no século XX foi a instituição do Código de Águas, datado de 1934. Esse documento vinha sendo trabalhado desde 1907, quando foi montado um primeiro projeto, e seu estabelecimento nos anos 30 foi muito importante para o desenvolvimento tanto das políticas posteriores para a área de saneamento, como para o setor de energia elétrica. O documento organizou e regulamentou a gestão das águas fluviais no país, centralizando a administração do assunto, com a transferência de diversas prerrogativas e incumbências dos estados e municípios para a União, como a fiscalização, aprovação de tarifas e concessão de lavras e quedas d'água. O código também previa que a União teria o poder de encampar concessões quando fosse do interesse público e previu a progressiva nacionalização das fontes de água e energia elétrica por força hidráulica. Essa centralização e institucionalização das políticas para o setor ganhou força com a criação do Conselho Federal de Forças Hidráulicas e Energia Elétrica (CFFHEE) e o Conselho Nacional de Águas e Energia Elétrica (CNAEE), em 1939. ${ }^{10}$

Mais especificamente em relação ao setor do saneamento, foi relevante a formação de uma agência específica no início do período Vargas. Apesar de se tratar de um órgão voltado inicialmente para uma intervenção local, a criação da Comissão de Saneamento da Baixada Fluminense, em 1933, é um marco no setor, tendo em vista ter sido um dos primeiros e mais impactantes organismos responsáveis por uma ação de saneamento, além de desenvolver políticas que se tornaram referência posteriormente nessa área. A agência era responsável pela realização de obras de saneamento no entorno da Baía de Guanabara e contratou serviços do principal engenheiro que atuava nesse ramo no período, Francisco Saturnino de Brito. Este havia atuado anteriormente na implementação de um sistema de saneamento na cidade de Santos, em 1907, e passou a desenvolver uma série de intervenções no recôncavo da Guanabara desde os anos 30, com a transformação de pântanos em pôlders, realização de aterros, diques, canalização de rios, erguimento de barragens, viadutos, obras auxiliares, preparação de terrenos

\footnotetext{
8 CRUZ, Maria Cecília Velasco e. O porto do Rio de Janeiro no século XIX: uma realidade de duas faces. Tempo. no 8. ago-dez de 1999, p. 1-18.

9 CAMPOS, Pedro Henrique Pedreira. Estranhas Catedrais: as empreiteiras brasileiras e a ditadura civilmilitar, 1964-1988. Niterói: Eduff, 2014.

10 CORRÊA, Maria Letícia. O Setor de Energia Elétrica e a Constituição do Estado no Brasil: o Conselho Nacional de Águas e Energia, 1939-1954. Tese de doutorado em História. Niterói: UFF, 2003.
} 
para a rodovia - em particular para a estrada Rio-São Paulo -, além da fertilização de solos e irrigação. ${ }^{11}$

Com esses empreendimentos, a região da Baixada Fluminense foi transformada em centro produtor de alimentos para o abastecimento da capital federal durante o período da II Guerra Mundial. A comissão na qual atuava o engenheiro sanitário Saturnino de Brito foi reformulada em 1940, quando passou a ter um alcance sobre todo o território brasileiro, transformada no Departamento Nacional de Obras de Saneamento (DNOS). O órgão era vinculado ao Ministério de Viação e Obras Públicas e tinha como atribuições a execução da política nacional de saneamento ambiental em áreas rurais e urbanas. Em 1962, o departamento foi transformado em autarquia federal. O DNOS foi, ao longo do século XX, o principal organismo responsável pela implementação das políticas nacionais de saneamento do Estado brasileiro. ${ }^{12}$

Um exemplo de intervenção na área de saneamento que envolvia interesses empresariais se deu com o abastecimento de água para o Rio de Janeiro nos anos 30 . No final dessa década, foi construída a adutora de Ribeirão das Lajes, obra que deveria prover estabilidade e regularidade ao abastecimento da então capital federal, antes dependente de pequenas adutoras que não garantiam um suprimento de água seguro e contínuo. A obra ficou a cargo da firma brasileira Dahne, Conceição \& Cia e gerou conflito com a Light, poderosa concessionária internacional de enorme presença sobre a economia brasileira naquele período. A Light possuía a concessão fluvial de Ribeirão das Lajes, além de outros rios do Vale do Paraíba. Houve uma medição de forças entre o governo varguista e a companhia estrangeira, mas a adutora acabou sendo construída, ficando pronta nos anos 40. A firma canadense realizou uma campanha difamatória na imprensa e no parlamento contra a obra, já que ela possuía um projeto próprio para o abastecimento de água à cidade do Rio de Janeiro, a partir do rio Guandu, obra que acabou sendo realizada nos anos 1950 e 1960, com a adutora Guandu-Leblon. ${ }^{13}$

Assim, em meio à reformulação do Estado brasileiro no período varguista, foram formados e consolidados órgãos de intervenção estatal que atuavam no setor do saneamento e vieram a ser lócus de atuação de interesses privados, aplicando políticas públicas que atendiam em boa medida aos objetivos de certos grupos econômicos. Cabe agora conhecer alguns desses agentes e suas organizações.

\section{Interesses empresariais associados às políticas para o setor do saneamento:}

A partir do desenvolvimento dos organismos e políticas voltadas para a área do saneamento, passaram a ser formadas empresas e organizações dedicadas ao tema. O setor estava inserido em um conjunto mais amplo de órgãos e políticas endereçadas ao segmento de infraestrutura que passou a se organizar no século XX principalmente com as reformulações inseridas pelo Estado varguista. Assim, várias empresas especializadas na realização de empreendimentos de engenharia mais complexos foram formadas nas décadas de 1920, 1930 e 1940. Houve, no período, o advento de um mercado de obras públicas no país, com a formação de um setor de construção pesada na indústria brasileira. Dentre outras atividades, como as

\footnotetext{
11 LAMEGO, Alberto Ribeiro. Setores da Evolução Fluminense. Volume 3: O Homem e a Guanabara. Rio de Janeiro: IBGE, 2007 [1948].

12LAMEGO, Alberto Ribeiro. O Homem e a Guanabara. Op. cit.; CAMPOS, Pedro Henrique Pedreira. Estranhas Catedrais. Op. cit.

13 PAULA, Dilma Andrade de. A Cidade Submersa: o processo de destruição de São João Marcos, 19301945. Dissertação de mestrado em História. Rio de Janeiro: UFRJ, 1994.
} 
estradas de rodagem e as ferrovias, essas empresas realizavam também obras de saneamento, sendo que algumas delas passaram a se especializar nesse segmento. ${ }^{14}$

Os empresários que fundaram e controlavam essas companhias muitas vezes eram engenheiros de formação, passando a atuar no setor privado após se formarem nas universidades ou desenvolveram atividade no setor público ou privado. E eles não atuavam isolada ou exclusivamente a partir das suas empresas. Desde os primórdios da formação do setor no Brasil, estavam organizados em aparelhos da sociedade civil. Assim, em 1880, foi formado o Clube de Engenharia. Esse órgão, desde suas origens, mais do que o nome sugere, não é apenas composto ou controlado por engenheiros de formação e profissão. Trata-se de um organismo que, desde a sua criação, é dominado e conduzido por empresários do setor da engenharia, com suas concepções de mundo, interesses e projetos específicos. Assim, historicamente, o organismo atua junto ao setor público, provendo quadros para a administração estatal, formulando diretrizes e projetos para a implementação das políticas e pautando a agenda do Estado. Sua força na Primeira República em particular foi notória, quando vários quadros do clube cumpriram a função de prefeitos do Distrito Federal, com administrações bastante impactantes, como a de Francisco Pereira Passos (1902-1906) e Carlos Sampaio (19201922). Através de seu periódico, a Revista do Clube de Engenharia, o órgão se expunha publicamente, com artigos e debates sobre grandes temas nacionais e da cidade do Rio de Janeiro. Assim, o órgão, por exemplo, foi um entusiasta das ações do DNOCS e publicava uma série de artigos sobre a questão do saneamento, pressionando pelo desenvolvimento das políticas para o setor, sendo Saturnino de Brito uma figura poderosa no clube, tendo presidido a entidade durante um período. ${ }^{15}$

O setor de obras públicas teve grande desenvolvimento na economia brasileira durante a década de 1950, em particular durante a gestão Kubitschek (1956-1961). Nesse período, foi implementado um extenso programa de empreendimentos de infraestrutura centrado nos setores de energia e transportes, em particular as obras de centrais hidrelétricas e estradas de rodagem. Outro projeto de grande porte implantado no período foi a construção da nova capital federal que exigiu serviços diversos de engenharia, inclusive na área de saneamento. Com o significativo volume de serviços de engenharia e a formação de grandes canteiros nas obras de Brasília e das rodovias, empresas de diferentes estados passaram a interagir e se aproximar, ao prestar serviços para órgãos contratantes comuns como a Novacap (Empresa Urbanizadora da Nova Capital Federal), o Departamento Nacional de Estradas de Rodagem (DNER) e o DNOS. Esses empresários passaram a se associar para deter as demandas dos trabalhadores da indústria da construção e para, juntos, acertarem preços e resultados de concorrência, além de combinarem esforços para pressionar por políticas favoráveis às suas empresas, bem como a realização de certas obras. Com isso, esses agentes formaram organizações nacionais reunindo as empresas do setor. ${ }^{16}$

Em 1957, foi fundada a Câmara Brasileira da Indústria da Construção (Cbic), que abrangia tanto empresários do setor imobiliário urbano, como os empreiteiros de obras públicas, com preponderância política dos primeiros. E, em 1959, foi fundada a Associação Profissional dos Empreiteiros de Estradas, Pontes, Portos, Aeroportos, Barragens e Pavimentação, que, no ano seguinte, tornou-se um sindicato, adotando a sigla Sinicon. Apesar de a cartela de obras discriminada pelo título do sindicato não contemplar o setor do saneamento, várias empresas filiadas ao Sinicon tinham atuação no setor e, ao longo da ditadura, o órgão atuava com muita

14 CHAVES, Marilena. Indústria da Construção no Brasil: desenvolvimento, estrutura e dinâmica. Dissertação de Mestrado em Economia Industrial. Rio de Janeiro: UFRJ, 1985.

15 HONORATO, Cézar Teixeira (org.). O Clube de Engenharia nos Momentos Decisivos da Vida do Brasil. Rio de Janeiro: Venosa, 1996; CURY, Vânia Maria. Engenheiros e Empresários: o Clube de Engenharia na gestão de Paulo de Frontin, 1903-1933. Tese de doutorado em História. Niterói: UFF, 2000.

16 LOPES, Luís Carlos. Brasília: o enigma da esfinge - a construção e os bastidores do poder. Porto Alegre / São Leopoldo: UFRGS / Unisinos, 1996. 
intensidade junto ao DNOS, demandando obras, sugerindo políticas e aproximando quadros empresariais do sindicato junto ao órgão público. ${ }^{17}$

Outro organismo que reunia empresários, que desenvolveu propostas e formulou projetos que tiveram impactos sobre o Estado e as políticas públicas foi o Instituto de Pesquisas e Estudos Sociais (Ipes). Fundado em 1961, no Rio de Janeiro, com outras sedes formadas posteriormente em capitais e cidades brasileiras, o Ipes reunia empresários, sobretudo os ligados ao capital internacional, com a presença também de militares, em particular os vinculados à Escola Superior de Guerra (ESG). Dentro da estrutura do Ipes, havia uma unidade intitulada "Reforma Habitacional (Estudo econômico e legal sobre casas populares)", conduzida por Sandra Cavalcanti e Guilherme Borghoff, ambos secretários do governo Carlos Lacerda no estado da Guanabara (1960-1965) e ligados ao capital imobiliário da cidade do Rio de Janeiro - tanto Cavalcanti como Borghoff tinham participação e atuação na construtora carioca Hosken Engenharia. ${ }^{18}$ Cavalcanti conduziu a política habitacional no antigo Distrito Federal, sendo responsável pela remoção de favelas em regiões nobres da cidade e a construção de conjuntos habitacionais padronizados em regiões periféricas e com poucos serviços públicos. A partir dessa experiência, ela ajudou a montar uma série de diretrizes de uma política nacional na área habitacional e foi nomeada pelo ditador Humberto Alencar de Castelo Branco, em 1964, para a presidência do recém-criado Banco Nacional de Habitação (BNH). Como veremos adiante, com o fito inicial de minimizar o déficit habitacional brasileiro, o BNH foi reorientado parcialmente ao longo da ditadura para pôr em prática as políticas da área de saneamento. O Ipes, assim, constituía-se como um espaço de acomodação de interesses privados, elaboração de projetos e propostas de políticas públicas de perfil classista, formação de intelectuais orgânicos e quadros para atuação na administração pública, além de formulação de programas que vieram a ser em boa medida incorporados à agenda estatal após o golpe de $1964 .{ }^{19}$

Apesar da importância do Clube de Engenharia, do Sinicon e do Ipes para a articulação de interesses e formulação de projetos de perfil empresarial para a adoção pelo Estado e nas políticas públicas, no que concerne ao setor do saneamento, um organismo da sociedade civil ganha protagonismo, ainda mais no período da ditadura. Em 1966 - em plena ditadura -, foi fundada, no Rio de Janeiro, a Associação Brasileira de Engenharia Sanitária e Ambiental (Abes), órgão central para a reunião de interesses e pressão junto às políticas públicas. Trata-se de uma associação sui generis, pois, apesar de ser formalmente privada e empresarial, reunia tanto empresas privadas que realizavam obras de saneamento, como empresas públicas, responsáveis pelas políticas estaduais para o setor do saneamento e que contratavam as firmas particulares. Apesar do estatuto privado, o grau de inserção junto ao aparelho de Estado possui tons realmente inéditos no caso dessa entidade. Assim, a sua primeira sede, nos anos 1960, funcionou em uma sala da Comissão de Planejamento de Esgoto Sanitário da Superintendência de Saneamento (Sursan), órgão do estado da Guanabara que, após a fusão, daria, junto com outros órgãos, origem à Cedae (Companhia Estadual de Águas e Esgotos do Estado do Rio de Janeiro). Com a extinção desse órgão, a Abes mudou a sua sede, na década de 1970, para um escritório no edifício-sede do Banco Nacional de Habitação (BNH), na Avenida Chile, centro do Rio. Assim, o órgão mantinha suas atividades em outro prédio público. ${ }^{20}$

17 SINICON. Dois Brasis: o que a infraestrutura está mudando. Cotia: Eolis Produções Culturais, 2009; CAMPOS, Pedro Henrique Pedreira. Estranhas Catedrais. Op. cit.

18 PESTANA, Marco Marques. Ampliação seletiva do Estado e remoções de favelas no Rio de Janeiro (19571973): embates entre empresariado do setor imobiliário e movimento dos favelados. Tese de doutorado em História. Niterói: UFF, 2018.

19 DREIFUSS, René Armand. 1964... Op. cit.

${ }^{20}$ ABES (Associação Brasileira de Engenharia Sanitária e Ambiental). Portal eletrônico da Abes. Disponível no endereço: http://www.abes-dn.org.br/ acessado no dia 24 de maio de 2011; CAMPOS, Pedro Henrique Pedreira. Estranhas Catedrais. Op. cit. 
Apesar da presença de integrantes das empresas estaduais de águas e esgotos, havia representantes do capital privado na entidade. Assim, em 1980, um diretor da Abes também estava na direção da Associação Paulista dos Empreiteiros de Obras Públicos (Apeop), órgão dos empresários da construção pesada do estado de São Paulo. Outro empresário integrante da Abes e muito ativo na entidade no início do seu funcionamento era Jaime Rotstein, engenheiro carioca dono da firma de engenharia Sondotécnica. Rotstein também era membro do Clube de Engenharia, organização na qual liderou uma das principais mobilizações dos empresários do setor durante a ditadura, a campanha "Em defesa da engenharia nacional", ${ }^{21}$ estabelecida durante o governo Castelo Branco (1964-1967) e que questionava a política dessa gestão de dar preferência às firmas estrangeiras de engenharia nas contratações por parte de órgãos governamentais. A campanha reuniu uma série de empresários do ramo da indústria da construção, principalmente ligados ao Clube de Engenharia e associações de classe do setor, tendo enorme êxito, já que redundou na reorientação da política estatal em relação ao tema na gestão Costa e Silva (1967-1969). Assim, como resultado da mobilização, foi expedido o decreto 64.345, de abril de 1969, que estabelecia a reserva de mercado no setor de obras públicas, restringindo exclusivamente às empresas nacionais a contratação por parte de órgãos públicos de serviços na área da engenharia. ${ }^{22}$

A Abes era filiada e representante no país da Asociación Interamericana de Ingeniería Sanitaria y Ambiental (Aidis) e publicava regularmente a revista Engenharia Sanitária. A associação defendia publicamente os investimentos no setor de saneamento junto às agências estatais. Segundo Jorge, ${ }^{23}$ a Abes se tornou uma porta-voz do sistema industrial e serviços privados e públicos ligados ao setor do saneamento. A entidade foi indutora e, ao mesmo tempo, ganhou força com o desenvolvimento das políticas para o setor durante a ditadura. Assim, ela cresceu em meio à implementação do Plano Nacional de Saneamento (Planasa), posto em prática a partir de 1971. Com o reforço das políticas no setor a partir de 1974, com o governo Geisel, que pôs em prática o Planasa-II, a Abes passou a desenvolver intensa interlocução junto a ministros, chefes e diretores de órgãos públicos, bem como outros representantes das agências estatais. A atuação da Abes também foi significativa junto ao Ministério do Interior durante a administração de Mário Andreazza (1979-1985) à frente da pasta. Andreazza, que havia sido ministro dos Transportes entre 1967 e 1974 e era muito próximo às empreiteiras de obras públicas e outros empresários, ganhou notoriedade ao colocar em prática um amplo programa de construção de casas populares e ações na área do saneamento durante a sua gestão. ${ }^{24}$

Se a Abes acumulou poder e foi interlocutora direta de agentes e agências do aparelho de Estado durante o auge da ditadura, na década de 1970, seu afastamento e viés mais crítico em relação ao Estado e às políticas estatais deram o tom da ação do órgão nos anos 80 , em meio à crise financeira e política vigente. Assim, com o corte de despesas para o setor, a entidade criticou o governo e alegou riscos à saúde pública com a decisão, afirmando que as principais lesadas com os cortes seriam as crianças. ${ }^{25}$

A Abes tinha uma dimensão nacional, atuando junto a organismos estatais federais. Já as companhias estaduais de saneamento eram alvo das ações das organizações regionais de empresários. Assim, por exemplo, desde a fusão dos estados do Rio de Janeiro e da Guanabara, em 1975, foram fundadas simultaneamente tanto a companhia estadual de saneamento fluminense, como uma organização de empresários de engenharia do novo estado da federação.

\footnotetext{
${ }^{21}$ ROTSTEIN, Jaime. Em Defesa da Engenharia Brasileira. Rio de Janeiro: Engenharia, 1966. mestrado em Ciência Política. Campinas: Unicamp, 1993.

23 JORGE, Wilson Edson. A Política Nacional de Saneamento Pós-64. Op. cit.

24 CAMPOS, Pedro Henrique Pedreira. Estranhas Catedrais. Op. cit.

25 JORGE, Wilson Edson. A Política Nacional de Saneamento Pós-64. Op. cit.
}

22 CAMARGOS, Regina Coeli Moreira. Estado e Empreiteiros no Brasil: uma análise setorial. Dissertação de 
A Associação dos Empreiteiros do Estado do Rio de Janeiro (Aeerj) tinha uma atuação intensa sobre órgãos do governo do estado, como o Departamento de Estradas de Rodagem do Rio de Janeiro (DER-RJ) e a Cedae. Durante o governo Leonel Brizola (1983-1986), em certas situações, a relação do empresariado com a administração estadual não foi amistosa. Assim, os empreiteiros da Aeerj afirmaram ter descoberto que obras de saneamento estavam sendo realizadas em Vilar dos Teles, no município de São João de Meriti, com empresas de fora do estado sem licitação, o que seria proibido. Atuando junto ao secretário de Obras, Luís Alfredo Salomão, conseguiram a interrupção dos trabalhos e, afirmando querer marcar posição, resolveram formar um consórcio com 19 empresas para entregar a obra "sem nada cobrar". Como esse tipo de ação era ilegal, as empresas cobraram a quantia simbólica de um centavo por ruas urbanizadas e por saneamento na região do município de São João de Meriti. Finalizado o serviço, a Aeerj publicou um anúncio no Jornal do Brasil e n'O Globo com o título "Empreiteiros do Rio: unidos!":

\begin{abstract}
As empresas doaram à Secretaria de Obras e Meio Ambiente e à CEDAE a execução do plano-piloto da rede de esgotos de Vilar dos Teles, perfazendo $13 \mathrm{~km}$ de extensão, bem como $6 \mathrm{~km}$ de ruas urbanizadas, que, agora, estão livres de águas poluídas, que, antes, corriam a céu aberto. Os serviços beneficiam diretamente 5 mil famílias.

As obras inauguradas custaram às empresas 1,5 bilhões de cruzeiros.

E o Estado não precisou gastar 1 só centavo.

O saneamento básico da Baixada Fluminense, melhoramento ansiosamente esperado pela população daquela região tão carente, já começou. Mas ainda há muito o que fazer.

O pessoal de lá sabe o quanto foi importante a união das empreiteiras para favorecer uma área tão necessitada.

Por isso, Vilar dos Teles está em festa.

E nem precisa agradecer. ${ }^{26}$
\end{abstract}

Nota-se no gesto dos empresários como eles quiseram exercer uma pressão sobre o aparelho de Estado no sentido de terem maior espaço na política estadual de saneamento e na realização de obras públicas no Rio de Janeiro.

Assim, vimos como os empresários estavam organizados com seus interesses em torno da política pública de saneamento. A Abes constituía a principal organização que reunia os interesses em torno das políticas de saneamento durante o período da ditadura, sendo composta tanto por empresários privados que atuavam no setor da engenharia, como por representantes de empresas públicas. Ao lado de outras organizações mencionadas - Clube de Engenharia, Aeerj (e organizações de empresários de outros estados), Sinicon e Ipes -, ela compunha a rede organizativa na sociedade civil que abrangia o setor empresarial com interesses e projetos para o setor do saneamento. Tendo em vista esses interesses organizados em associações privadas, vejamos agora em linhas gerais as políticas estatais desenvolvidas para o setor do saneamento durante a ditadura.

\title{
Políticas públicas endereçadas para o setor do saneamento durante a ditadura
}

A área social não constituiu um dos fortes da ditadura brasileira no que diz respeito às suas políticas e prioridades. Com o intenso aparato repressor do regime e os canais de reivindicação popular obstruídos, as áreas destinadas aos investimentos se concentravam em empreendimentos do interesse direto dos grupos dominantes da sociedade, como as vias para o escoamento de mercadorias e grandes centrais elétricas para gerar energia barata para

26 AEERJ. AEERJ 30 Anos: 30 anos de obras públicas no Rio de Janeiro (1975-2005). Rio de Janeiro: AEERJ, 2005 [1984], p. 53-54. 
consumidores industriais. A ditadura chegou a reduzir o orçamento das áreas sociais em favor dos gastos dos ministérios militares e os voltados para a infraestrutura de transportes e energia. Assim, os dispêndios do Ministério da Saúde foram reduzidos de 4,29\% para 0,99\% do orçamento geral da União entre os anos de 1966 e 1974. O Ministério da Educação viu a sua fatia no orçamento público minguar de 11,07\% para 4,95\% entre 1965 e 1974 . Neste último ano, enquanto a Saúde possuía 0,99\% e a Educação detinha 4,95\% do orçamento federal, o Ministério dos Transportes acumulava 9,35\% dos gastos da União. ${ }^{27}$

O Ministério do Interior constituía a agência estatal fundamental na qual estavam concentradas as organizações e políticas voltadas para o setor do saneamento e áreas correlatas. Assim, estavam subordinadas à pasta instâncias como o DNOS, o DNOCS e o aparato de habitação formado pelo regime. A presença de oficiais militares conduzindo a pasta durante a ditadura era constante, sendo o ministério comandado pelo general Afonso Augusto de Albuquerque Lima durante o governo Costa e Silva (1967-1969), pelo general José da Costa Cavalcanti no governo Médici (1969-1974) e pelo coronel Mario David Andreazza durante a presidência de João Batista Figueiredo (1979-1985). O ministério era voltado para a política urbana e regional, sendo uma ideia norteadora de suas atividades a redução das assimetrias de desenvolvimento entre as regiões do país. Suas atividades estiveram muito ligadas à região Nordeste, com um forte peso dos grupos políticos e econômicos locais sobre as suas autarquias e políticas, em particular a Superintendência de Desenvolvimento do Nordeste (Sudene), órgão criado em $1957 .{ }^{28}$

Apesar da existência de agências antigas e notórias sob o guarda-chuva do Ministério do Interior, o órgão da pasta que mais teve proeminência durante a ditadura foi o Banco Nacional de Habitação (BNH). O organismo teve mesmo uma certa identificação com o regime, tendo em vista que ele foi formado poucos meses após o golpe de 1964, durante o governo Castelo Branco, e extinto apenas um ano após o fim do mandato do último general-presidente, em 1986. A criação do banco estava inserida em uma reorganização das agências e das políticas estatais para o setor de habitação. Assim, uma ampla reestruturação do setor envolveu a extinção de organismos que atuavam no campo da habitação anteriormente, como a Fundação Casa Popular (FCP) e os institutos de aposentadorias e pensões (IAP's) das diferentes categorias profissionais, como os industriários, comerciários etc. Substituindo essas agências e com um modelo bem mais complexo e diferenciado, foram criados logo em 1964, além do BNH, o Sistema Federal de Habitação (SFH), o Serviço Federal de Habitação e Urbanização (Serfhau), as companhias de habitação (Cohab's), todas elas implicadas no Plano Nacional de Habitação. ${ }^{29}$

Como vimos, a formação do BNH e do aparato habitacional da ditadura remonta à administração de Sandra Cavalcanti e outros agentes no governo estadual Lacerda na Guanabara, bem como na elaboração de propostas e projetos para o setor por parte de Cavalcanti e outros agentes no âmbito do Ipes. É importante salientar a significativa presença de empresários, tanto na formulação da proposta de reorganização do sistema habitacional brasileiro, como na condução das principais agências do setor ao longo da ditadura. Assim, Sandra Cavalcanti, primeira presidente do BNH, era ligada à construtora carioca Hosken Engenharia que havia sido beneficiada por remoções e oportunidades imobiliárias na zona Sul da cidade do Rio de Janeiro durante a gestão Lacerda. Em 1971, a Hosken erguia prédios na área da antiga favela da Praia do Pinto, no Leblon, removida quando Sandra Cavalcanti era secretária estadual. ${ }^{30}$ Atuando junto com ela no Ipes estava o empresário Carlos Moacyr Gomes,

\footnotetext{
27 JORGE, Wilson Edson. A Política Nacional de Saneamento Pós-64. Op. cit.; CAMPOS, Pedro Henrique Pedreira. Estranhas Catedrais. Op. cit.

28 CAMPOS, Pedro Henrique Pedreira. Estranhas Catedrais. Op. cit.

29 FONTES, Virgínia. Continuidades e Rupturas na Política Habitacional Brasileira, 1920-1979. Dissertação de mestrado em História. Niterói: UFF, 1986.
}

30 O Empreiteiro. Edição de outubro de 1972, nº 57. 
dono da Gafisa, uma das maiores empresas do mercado imobiliário carioca nos anos $60 .{ }^{31}$ Vários diretores do BNH ao longo da ditadura eram oriundos do segmento empresarial, como João Machado Fortes, dono da construtora que leva o seu nome e que foi diretor da Carteira de Cooperativas do BNH em 1966, ao mesmo tempo em que cumpria a função de presidente do Sindicato da Indústria da Construção de Estruturas do Estado da Guanabara. ${ }^{32}$ De forma similar, de acordo com a revista O Empreiteiro, o empresário Oscar Klabin Segall presidia a Companhia Estadual de Casas Populares de São Paulo em 1979. ${ }^{33}$

O BNH foi formado após uma carta enviada por Sandra Cavalcanti a Humberto Alencar de Castelo Branco. No documento, a secretária do governo Lacerda argumentava que era necessário atender a algumas demandas das classes populares, como a necessidade de moradias nas áreas urbanas. Alegava-se que, naquele período, o déficit habitacional brasileiro alcançava um total de 8 milhões de moradias. ${ }^{34}$ Dessa forma, um dos objetivos do BNH foi gerar uma contrapartida às classes subalternas à política de compressão salarial, repressão e perseguição aos sindicatos realizada pela ditadura. Está claro que, na condição de empresária do setor da indústria da construção, Cavalcanti omitia os interesses do seu grupo social na proposta de formação de uma agência que captaria poupanças compulsórias da sociedade e canalizaria para os grupos econômicos que atuavam no setor da construção civil. O banco também se configurava enquanto um mecanismo de intervenção econômica para a criação de empregos, que acabava por ser a principal 'política social' da ditadura. Isso porque a indústria da construção - tanto a de edifícios urbanos como no segmento de obras de infraestrutura - empregava numerosa força de trabalho no período, além de suas atividades acionarem cadeias produtivas significativas nos setores de materiais de construção e equipamentos, ramos francamente com base industrial no país. Assim, Ferreira destaca o papel do $\mathrm{BNH}$ e de seus financiamentos na criação de empregos no período. ${ }^{35}$

Originalmente, o BNH era destinado sobretudo ao financiamento da construção de moradias populares. No entanto, o banco operava com a lógica de que os empréstimos não deveriam possuir subsídio, de modo que o comprador deveria arcar com os recursos para a compra da sua habitação. A combinação dessa diretriz com a política de "arrocho salarial" inibiu as possibilidades de os integrantes da classe trabalhadora adquirirem suas casas com os empréstimos oriundos do banco, tendo em vista o elevado peso que as prestações compunham nos gastos mensais das famílias dos trabalhadores. Com isso, os financiamentos do BNH foram sendo endereçados para a construção e aquisição de imóveis para a classe média. $O$ banco passou a dotar dos recursos do Fundo de Garantia por Tempo de Serviço (FGTS) desde 1967, havendo com isso uma majoração significativa dos recursos controlados pelo órgão que eram canalizados para os grupos econômicos que atuavam no setor da construção. ${ }^{36}$

No entanto, durante o governo Médici, o BNH viu ampliar suas prerrogativas e raio de ação. Em 14 de dezembro de 1971, a lei 5762 transformou o órgão em uma empresa pública e o banco passou a atuar não só no setor de habitação, mas também ficou responsável por conduzir em parte a política nacional de saneamento, além de dotar recursos para outros projetos na área de infraestrutura. Assim, o BNH foi o responsável pela principal iniciativa da ditadura para o setor, com o lançamento do Plano Nacional de Saneamento (Planasa), em 1971. O plano estabelecia metas bastante ambiciosas para a ampliação da rede de coleta de águas e

\footnotetext{
31 DREIFUSS, René Armand. 1964: a conquista do Estado. Op. cit.

32 FONTES, Virgínia. Continuidades e Rupturas... Op. cit.

33 O Empreiteiro. Edição de junho de 1979, n 137.

34 FERREIRA, Carlos Ernesto. Construção Civil e Criação de Empregos. Rio de Janeiro: EdFGV, 1975.

35 FERREIRA, Carlos Ernesto. Construção Civil e Criação de Empregos. Op. cit.

36 FONTES, Virgínia. Continuidades e Rupturas... Op. cit.
} 
esgotos das cidades brasileiras até o ano de 1980. Antes disso, o DNOS havia feito um convênio com a United States Agency for International Development (Usaid), mas as políticas para o setor ganharam um novo porte com a formação do Planasa. A partir deste projeto, o BNH ficaria responsável pelo financiamento de empreendimentos como interceptadores oceânicos, emissários submarinos, estações de tratamento, além de sistema de fornecimento de águas e esgotos para as regiões urbanas do país. O Planasa incluía a formação do Sistema Financeiro do Saneamento (SFS) que centralizava os recursos destinados ao setor, ampliados de forma significativa ao longo da década de 1970. O plano era baseado na adoção das tarifas realistas, sem subsídio, o que deveria garantir a viabilidade financeira do sistema. A criação do SFS incentivou a formação das companhias estaduais de saneamento, que contariam com os recursos do BNH e do Fundo de Financiamento para Água e Esgotos (FAE). Dentre essas empresas estaduais, a maior era a Sabesp (Companhia de Saneamento Básico do Estado de São Paulo), seguida da Cedae, Copasa (MG) e Embasa (BA). ${ }^{37}$

O governo Geisel centrou ainda mais esforços na política destinada para o setor de saneamento ao lançar, em 1974, o Planasa-II com metas ousadas de atendimento do fornecimento de águas e esgotos para regiões urbanas do país, com ênfase nas maiores cidades do Sudeste e Nordeste. A população atendida por água e esgotos do país passou de $44,5 \%$ em 1970 para $79,8 \%$ em 1983, sendo que o Planasa-II previa chegar à cifra de $90 \%$ em 1990 . No entanto, os índices referentes à rede de esgoto sanitário eram bem inferiores, havendo também intenso desnível entre as regiões do país. ${ }^{38}$

No período final da ditadura, foram intensificadas as ações estatais na política de saneamento e nas áreas de impacto social. Consoante a abertura do regime, a crescente mobilização e manifestação popular, os expressivos resultados eleitorais da oposição à ditadura, foram intensificados os investimentos em habitação popular, transporte público de massa e redes de saneamento, em prejuízo dos projetos valorizados no período do "milagre" (19681973), como as grandes rodovias e usinas hidrelétricas. O BNH voltou a enfatizar a construção de moradias populares e ampliou as metas de construção de casas, passando ao financiamento das obras de 97 mil unidades habitacionais em 1974 para 339 mil em 1978. 39 Durante o governo Figueiredo, foi estabelecida a meta mais ousada para construção habitacional, com o objetivo de construir um total de 6 milhões de residências ao longo do mandato, com média de um milhão de casas por ano. A meta não foi atingida, mas esse acabou sendo o período de maior construção habitacional da história do país. O programa para habitação e saneamento era conduzido por Mário David Andreazza que depois tentou ser candidato à presidência da República pelo PDS, partido oriundo da Arena, perdendo as prévias para o candidato Paulo Maluf. A gestão do ministro do Interior incluiu extenso conjunto de obras, como o Promorar (Programa para Erradicação da Sub-Habitação), na comunidade da Maré, no Rio de Janeiro, e em Alagados, em Salvador. ${ }^{40}$

Apesar dos dados quantitativos superlativos, a qualidade das moradias nem sempre era a mais adequada. Para a implementação de grandes conjuntos habitacionais no período foram adquiridos terrenos baratos, em regiões longínquas dos grandes centros urbanos, com dificuldade de acesso dos seus moradores aos locais de trabalho e serviços públicos. Moradores de um conjunto habitacional financiado pelo BNH em Fazenda Botafogo, no Rio de Janeiro, queixavam-se de que as casas tinham telhas de amianto, material que retém o calor e tem efeito cancerígeno. As unidades tinham pé direito de 2,2 metros e tamanhos de apenas 35 a 44 metros quadrados, sendo as paredes construídas sem reboco e com pintura diretamente nos tijolos.

\footnotetext{
37 JORGE, Wilson Edson. A Política Nacional de Saneamento Pós-64. Op. cit.

38 O Empreiteiro. Edição de abril de 1975, nº 87.

39 JORGE, Wilson Edson. A Política Nacional de Saneamento Pós-64. Op. cit.

40 O Empreiteiro. Edição de março de 1984, nº 196.
} 
Inexistiam equipamentos coletivos, como praças, escolas, creches e postos de saúde. Nessa época, consolidou-se também o padrão dos prédios financiados pelo BNH com plantas em formato de ' $\mathrm{H}$ ', o que demandava serviços de modificação da topografia dos terrenos, exigindo obras de terraplanagem feitas pelas grandes empreiteiras com equipamentos. Assim, nota-se como as metas ousadas de construção habitacional estavam relacionadas à precariedade das habitações construídas e os interesses para obras padronizadas a cargo de construtoras oriundas do setor da construção pesada. ${ }^{41}$

Os empresários estavam atentos a essas novas prioridades. Assim, o presidente do Sinicon, Jorge Luiz de la Rocque afirmou publicamente em 1977 que as empreiteiras deveriam esquecer as oportunidades na construção rodoviária e atuar mais nos setores de energia e saneamento. ${ }^{42}$ De forma similar, Joseph Young, responsável pela revista O Empreiteiro redigiu em editorial de abril de 1980: "O povo está na rua exigindo os seus direitos. Se tivermos dinheiro, devemos aplicar em transporte de massa, saneamento básico e habitação popular. Não em elefantes brancos". ${ }^{43}$

Dessa forma, verificamos como a ditadura desenvolveu políticas bastante impactantes para o setor do saneamento, sobretudo a partir dos anos 70, utilizando-se das novas agências formadas após o golpe de Estado. Vejamos agora como em alguns projetos específicos fica evidente como essas políticas destinadas ao ramo do saneamento atendiam significativamente aos interesses e projetos do capital privado, sobretudo o da indústria da construção.

\section{Grandes projetos da ditadura para o setor do saneamento e seus beneficiários:}

A montagem de políticas estruturadas nacionais específicas para o setor do saneamento na década de 1970, com metas de cobertura do fornecimento de água e esgotos para um montante mais significativo da população, chamou a atenção de certos segmentos empresariais para oportunidades na área. A destinação de recursos próprios geridos pelo BNH, captados dos depósitos compulsórios do FGTS e outras fontes, formou uma fatia particular do fundo público para intervenções na área de saneamento, na época turbinados com a alta liquidez disponível no mercado internacional. Assim, a formação do Planasa do SFS chamou a atenção de interesses privados para possíveis fontes de faturamento e lucro no segmento do saneamento. As características de alguns dos principais projetos financiados pela política nacional de saneamento tinham como norma a forma das grandes soluções expressas em projetos grandiloquentes que atendiam especificamente a certos interesses bem delimitados. Conforme afirmou Jorge: "O setor de saneamento urbano mostrou-se um excelente negócio para as grandes empreiteiras (leia-se sub-setor de construção pesada), dentro do sistema montado para financiar e gerir a política de saneamento". ${ }^{44}$

Assim, algumas das principais iniciativas do Planasa, contando com financiamento do $\mathrm{BNH}$, foram expressas na forma de grandes projetos de engenharia que eram especialmente interessantes para as empreiteiras de obras públicas. Essas empresas viram grandes oportunidades serem formadas com a orientação específica do fundo público para o setor do saneamento e, com isso, foram atendidas também empresas que compunham a cadeia produtiva da indústria de construção, com destaque para os materiais e equipamentos. Ao invés de propor pequenas soluções e obras de menor porte, as agências estatais propunham soluções de grande

\footnotetext{
41 O GLOBO. Série 'Vidas em Blocos'. Edição de 11 de maio de 2011.

42 O Empreiteiro. Edição de abril de 1977, n 111.

43 O Empreiteiro. Edição de abril de $1980, n^{\circ} 147$, p. 3.

44 JORGE, Wilson Edson. A Política Nacional de Saneamento Pós-64. Op. cit., p. 7.
} 
impacto e com projetos de grande monta. Um exemplo disso foi a construção dos emissários submarinos. Com vistas a conter a poluição das praias litorâneas, foram montados planos para construção de longas estruturas de engenharia para despejar o esgoto urbano em regiões afastadas da costa. Na década de 1970, foram construídos emissários submarinos em várias cidades brasileiras, com obras bastante complexas e contratadas junto a empreiteiras de grande porte. Os emissários eram feitos de diferentes materiais, sendo de aço em Santos, plástico nos de Manaus e Vitória, e concreto protendido no Rio e em Salvador. ${ }^{45}$

Dentre esses projetos, ganha destaque o emissário submarino da cidade do Rio de Janeiro, o primeiro a ser construído e o de maior porte entre todos os arrolados. A construção do emissário de Ipanema ficou a cargo da Empresa de Saneamento de Águas da Guanabara (Esag), empresa que foi uma das que deu origem à Cedae, formada após a fusão dos estados do Rio de Janeiro e da Guanabara, em 1975. A obra estava associada à construção do interceptador oceânico, uma rede de canos que impedia o despejo de esgotos nas praias de Copacabana e Ipanema, levando-o ao emissário submarino. No espírito das obras do "Brasil grande", a propaganda do regime assinalava que este seria o quinto maior emissário submarino do mundo, com um total de $4,5 \mathrm{~km}$ de extensão. $O$ objetivo propalado pelo governo era a "despoluição das águas oceânicas", com vistas ao incremento do turismo e da frequência nas mundialmente famosas praias de Copacabana e Ipanema. O empreendimento feito na década de 1970 deveria ser acompanhado da construção de uma estação de tratamento de esgotos (ETE), que nunca foi realizada. Um dos motivos alegados para a não-construção da ETE é que sua localização na região poderia gerar mal-estar e incômodo aos vizinhos, por conta do mau cheiro e outros inconvenientes, sendo aquela uma zona nobre da cidade do Rio, com terrenos altamente valorizados. Sem a ETE, depois da obra pronta, o esgoto de boa parte do Rio, incluindo praticamente toda a zona Sul e centro da cidade, era despejado in natura, sem tratamento, a pouco mais de quatro quilômetros da praia de Ipanema. A obra foi feita inicialmente pela empreiteira paulista Constran que acabou perdendo o contrato em 1969, cedendo-o para a construtora Bahia, que finalizou a obra com o auxílio de grupos estrangeiros. ${ }^{46}$

Outro grande projeto de saneamento implementado em meio aos programas do Planasa e que também abrangia a afeição pelas soluções de grande porte e o atendimento dos interesses empresariais das construtoras e outros grupos econômicos associados foi o do Sistema de Abastecimento da Grande São Paulo (Sanegran). Esse era outro plano faraônico da ditadura, que previa a construção da maior estação de tratamento esgotos contínua do mundo, com emissários longos e de grande diâmetro, atravessando inclusive rios. O projeto era tão custoso que absorvia parcela significativa do orçamento nacional para o setor de saneamento nos anos 70 e 80. Assim, a maioria dos investimentos em saneamento no estado de São Paulo estava concentrada na região metropolitana, perfazendo entre 74 e $97 \%$ dos gastos em toda a federação entre 1975 e 1981. Além disso, entre 1973 e 1984, o estado de São Paulo recebeu $77 \%$ dos gastos nacionais na área de saneamento, sendo que boa parte desses recursos era endereçada ao projeto Sanegran. ${ }^{47}$ Ao contrário da zona Sul do Rio de Janeiro, a unidade de tratamento de Barueri foi construída, afetando a vida das pessoas do entorno, com o mau cheiro e inconvenientes da unidade de tratamento. A região não era tão nobre e valorizada quanto a prevista para a ETE do Rio e o projeto em São Paulo teve acusações de favorecimento dos projetos imobiliários da Brascan, fartamente beneficiada em outras ocasiões em ações estatais desenvolvidas nas cidades do Rio e São Paulo. ${ }^{48}$

\footnotetext{
45 O Empreiteiro. Edição de abril de 1977, n 111.

46 O Empreiteiro. Edições de outubro de 1974, n 81; setembro de 1976, n 104; abril de $1977, \mathrm{n}^{\circ} 111$.

47 JORGE, Wilson Edson. A Política Nacional de Saneamento Pós-64. Op. cit.

48 BENCHIMOL, Jaime Larry. Pereira Passos. Op. cit.
} 
O projeto foi posto em prática por grandes construtoras paulistas, com destaque para a empreiteira Camargo Corrêa, a maior empresa de engenharia do país durante toda a ditadura e a principal responsável pelo projeto. Na realização dos trabalhos do Sanegran, a Camargo Corrêa utilizou os shields, ou "tatuzões", que são máquinas perfuratrizes que agem no subsolo e que estavam ociosas depois de terem sido usadas nas obras do metrô da cidade de São Paulo. Em sua memória, o alto dirigente da empresa, Wilson Quintella, ${ }^{49}$ relata como a empreiteira venceu a licitação para a construção de trechos da linha inicial do metrô de São Paulo. O edital previa o método cut and cover, com abertura das fendas onde seriam colocados os trilhos e cobertura posterior. Mas a construtora possuía relatórios técnicos de especialistas ingleses que verificaram que aquele método era inviável para o trecho licitado do metropolitano, implicando na demolição de vários edifícios. Com isso, a empreiteira apresentou um lance muito baixo na concorrência, venceu a licitação e, em seguida, apresentou à Companhia do Metropolitano Urbano o relatório técnico que demonstrava que seria necessário o uso dos equipamentos shields naquela obra. Assim, a Camargo Corrêa manteve os contratos das obras e conseguiu significativos aditivos por se tratar de um método construtivo mais complexo e com a demanda de compra dos "tatuzões" que foram adquiridos na Alemanha Ocidental pela empresa. Após usar os shields na obra metrô, a Camargo Corrêa conseguiu manter o uso dos equipamentos, utilizando-os nas obras do Sanegran, adaptadas ao uso dessas máquinas.

As peripécias da empreiteira Camargo Corrêa para a obtenção de contratos e maximização dos seus lucros via apropriação do fundo público não constituíam novidades e não se interromperam aí. Pelo contrário. A empreiteira controlada por Sebastião Camargo era a maior empresa de engenharia do país e um dos maiores grupos econômicos privados brasileiros nas décadas de 70 e 80. A Caterpillar, maior fabricante de equipamentos de construção do mundo, chegou a indicar a empresa como a construtora com mais máquinas com a sua marca em todo o planeta no início da década de 80,50 o que postulava a Camargo Corrêa à virtual condição de maior empreiteira do mundo no período. Além disso, seu controlador, Sebastião Camargo, foi o primeiro brasileiro a constar na lista internacional de bilionários da Forbes e da Fortune, também no início dos anos $1980 .{ }^{51}$ Por fim, trata-se de um grupo econômico estreitamente vinculado à ditadura, aos militares e até mesmo ao aparato de terrorismo de Estado do regime. Assim, a empreiteira era uma das principais contribuidoras da Operação Bandeirantes, iniciativa da ditadura para desmantelar os grupos de resistência armada à ditadura, que utilizava métodos como detenções ilegais, tortura e assassinatos. Por conta disso, alguns grupos da luta armada cogitaram o "justiçamento" de Sebastião Camargo dada a sua cooperação com os mecanismos de terror de Estado da ditadura. Antes, no entanto, o Movimento Revolucionário Tiradentes (MRT) e a Aliança Nacional Libertadora (ALN) assassinaram Henning Boilesen, dirigente do grupo Ultragás, também ativo colaborador da Oban. ${ }^{52}$

O grande capital do setor da construção pesada se interessou tanto pelo ramo do saneamento que obteve, por conta de seu poder de pressão, a limitação das concorrências públicas a poucos grupos econômicos. Assim, na década de 1980, o Sindicato dos Engenheiros de Minas Gerais criticou publicamente os editais que eram lançados para os empreendimentos e serviços de saneamento, apontando que os mesmos limitavam sem uma justificativa razoável as concorrências a um pequeno número de empresas de engenharia, com maior capacidade técnica e de capital. ${ }^{53}$

\footnotetext{
49 QUINTELLA, Wilson. Memórias do Brasil Grande: a história das maiores obras do país dos homens que as fizeram. São Paulo: Saraiva / Vigília, 2008.

50 Idem.

51 PINTO, Lúcio Flávio. Tucuruí: a barragem da ditadura. Belém: Edição do autor, 2010.

52 MELO, Jorge José de. Boilesen, um Empresário da Ditadura: a questão do apoio do empresariado paulista à Oban/Operação Bandeirantes. Dissertação de mestrado em História. Niterói: UFF, 2012.

53 JORGE, Wilson Edson. A Política Nacional de Saneamento Pós-64. Op. cit.
} 
Por fim, projetos de saneamento chegaram a compor a pauta final das políticas da ditadura e mesmo a agenda de uma candidatura decorrente do regime. Assim, no início da década de 1980, o ministro do Interior Mário Andreazza anunciou o "Projeto Nordeste", ou Nordestão, prevendo um conjunto de investimentos que focavam o semi-árido nordestino e totalizavam US\$ 12 bilhões em obras de engenharia na região ao longo de 15 anos, estendendose até o ano de 1999, com previsão de ciração de 1,5 milhão de empregos. O projeto incluía os programas Pólo-Nordeste, Sertanejo, Pró-hidro, Pró-várzeas, com ênfase na área de saneamento, incluindo a transposição das águas do rio São Francisco para o atendimento da demanda do interior dos estados do Nordeste. Seu esquema de financiamento incluía também instituições nacionais, como a Brasilinvest, de Mário Garnero, empresa que depois entrou em decadência e foi acusada de denúncias de corrupção. O Nordestão contava com recursos do Banco Mundial e foi parcialmente executado durante o governo Figueiredo (1979-1985), sendo utilizado como emblema da candidatura de Andreazza à presidência da República em 1984. ${ }^{54}$ Andreazza disputou com outros nomes a indicação como candidato do PDS à presidência da República e acabou perdendo o pleito para Paulo Maluf que seria derrotado por Tancredo Neves nas eleições indiretas realizadas em janeiro de 1985. Vários apoiadores de Andreazza eram políticos tradicionais do Nordeste, ligados à ditadura, e que acabaram formando a Frente Liberal que deu suporte à chapa de Tancredo, como é o caso da figura de Antonio Carlos Magalhães. A candidatura de Andreazza dispunha de franca simpatia por parte das empreiteiras de obras públicas que temeram pela descontinuidade do Projeto Nordeste após a sua derrota nas prévias do PDS, como de fato ocorreu.

\section{Conclusão - quem ganha e quem perde com a lógica dos grandes projetos}

Vimos, ao longo deste artigo, como o setor do saneamento foi paulatinamente sendo transformado em objeto de política pública, com a formação de agências estatais específicas competentes pelo assunto, durante o século XX. Foram organizados no âmbito da sociedade civil interesses privados em torno dos projetos de saneamento, atentos às obras que os mesmos acarretavam. Durante a ditadura, foram montados ousados programas de ampliação da rede de abastecimento de águas e esgotos nas maiores cidades brasileiras. Em um momento de intensificação do processo de êxodo rural e inchaço das principais metrópoles do país, foram elaborados grandes projetos para a área de saneamento, contando com montantes significativos de recursos, formados a partir da reformulação do sistema financeiro nacional, da montagem das poupanças compulsórias e pelo significativo crédito externo disponível no período. Com isso, fortaleceu-se o padrão de desenvolvimento de grandes soluções para os problemas de saneamento das cidades brasileiras, com a formulação de projetos maiúsculos de engenharia, que acarretavam o uso de equipamentos sofisticados e a realização das intervenções por construtoras de grande porte, bastante poderosas politicamente na correlação de forças daquele período. Com isso, a política de saneamento era orientada em boa medida para o atendimento dos interesses desses grupos econômicos, em detrimento da demanda e do atendimento das necessidades de maior parte da população.

Apesar de essa situação específica ser bem representativa da ditadura e da arquitetura política do período, com afastamento dos grupos subalternos do processo decisório e intensa presença dos grandes grupos econômicos internacionais e brasileiros no processo de definição da agenda estatal, movimentos recentes da política de saneamento verificadas no país indicam algumas semelhanças com o ocorrido naquela época. Assim, as recentes crises das empresas públicas de abastecimento e da oferta à população do direito ao serviço de água e esgotos com

54 O Empreiteiro. Edição de setembro de 1984, n 202; Informe Sinicon. Edição de 6 de fevereiro de 1984, $\mathrm{n}^{\circ} 1$, ano I. 
qualidade e as propostas de privatização dessas companhias estatais sinalizam que a intenção de atendimento a certos interesses empresariais específicos em detrimento das demandas populares parece continuar constituindo certo padrão das políticas de saneamento no país no período atual. Mesmo com as flagrantes diferenças que separam o regime ditatorial do sistema democrático liberal inaugurado pela Constituição de 1988, a capacidade de grupos econômicos privados - muitas vezes formados, alimentados e consolidados sob a ditadura - para pressionar as diretrizes e práticas das políticas estatais no setor do saneamento nos dias atuais parece ser algo notório na sociedade brasileira no momento presente. 


\section{Referências}

ABES (Associação Brasileira de Engenharia Sanitária e Ambiental). Portal eletrônico da Abes. Disponível no endereço: http://www.abes-dn.org.br/ acessado no dia 24 de maio de 2011.

AEERJ. AEERJ 30 Anos: 30 anos de obras públicas no Rio de Janeiro (1975-2005). Rio de Janeiro: AEERJ, 2005.

BENCHIMOL, Jaime Larry. Pereira Passos: um Haussmann tropica; a renovação urbana da cidade do Rio de Janeiro no início do século XX. Rio de Janeiro: Secretaria Municipal de Cultura, 1992.

BRESCIANI, Maria Stella. Londres e Paris no Século XIX: o espetáculo da pobreza. São Paulo: Brasiliense, 1981.

CAMARGOS, Regina Coeli Moreira. Estado e Empreiteiros no Brasil: uma análise setorial. Dissertação de mestrado em Ciência Política. Campinas: Unicamp, 1993.

CAMPOS, Pedro Henrique Pedreira. Estranhas Catedrais: as empreiteiras brasileiras e a ditadura civil-militar, 1964-1988. Niterói: Eduff, 2014.

CAMPOS, Pedro Henrique Pedreira. Empresariado e ditadura no Brasil: fontes, métodos e historiografia. Sillogés, v. 3, 2020, p. 15-42.

CHAVES, Marilena. Indústria da Construção no Brasil: desenvolvimento, estrutura e dinâmica. Dissertação de Mestrado em Economia Industrial. Rio de Janeiro: UFRJ, 1985.

CORRÊA, Maria Letícia. O Setor de Energia Elétrica e a Constituição do Estado no Brasil: o Conselho Nacional de Águas e Energia, 1939-1954. Tese de doutorado em História. Niterói: UFF, 2003.

CRUZ, Maria Cecília Velasco e. O porto do Rio de Janeiro no século XIX: uma realidade de duas faces. Tempo. no 8. ago-dez de 1999, p. 1-18.

CURY, Vânia Maria. Engenheiros e Empresários: o Clube de Engenharia na gestão de Paulo de Frontin, 1903-1933. Tese de doutorado em História. Niterói: UFF, 2000.

DREIFUSS, René Armand. 1964: a conquista do Estado; ação política, poder e golpe de classe. Petrópolis: Vozes, 1981.

ENGELS, Frederich. A Situação da Classe Trabalhadora na Inglaterra. São Paulo: Global, 1988 [1845].

FERRAZ Filho, Galeno Tinoco. A Transnacionalização da Grande Engenharia Brasileira. Dissertação de mestrado em Economia. Campinas: PPGE/Unicamp, 1981.

FERREIRA, Carlos Ernesto. Construção Civil e Criação de Empregos. Rio de Janeiro: EdFGV, 1975.

FONTES, Virgínia. Continuidades e Rupturas na Política Habitacional Brasileira, 1920-1979. Dissertação de mestrado em História. Niterói: UFF, 1986.

GLOBONEWS. Programa Cidades e Soluções. Com André Trigueiro, Fabiano Thompson e Adacto Ottoni. Gravado e publicado em 21/01/2020. Disponível no endereço: https://www.youtube.com/watch?v=NiMJLuvA2Kc\&t=770s acessado em 21/02/2020.

HONORATO, Cézar Teixeira (org.). O Clube de Engenharia nos Momentos Decisivos da Vida do Brasil. Rio de Janeiro: Venosa, 1996.

Informe Sinicon. Edição de 6 de fevereiro de 1984, n 1, ano I. 
JORGE, Wilson Edson. A Política Nacional de Saneamento Pós-64. Tese de doutorado em Arquitetura e Urbanismo. São Paulo: USP, 1987.

LAMEGO, Alberto Ribeiro. Setores da Evolução Fluminense. Volume 3: O Homem e a Guanabara. Rio de Janeiro: IBGE, 2007 [1948].

LOPES, Luís Carlos. Brasília: o enigma da esfinge - a construção e os bastidores do poder. Porto Alegre / São Leopoldo: UFRGS / Unisinos, 1996.

MELO, Jorge José de. Boilesen, um Empresário da Ditadura: a questão do apoio do empresariado paulista à Oban/Operação Bandeirantes. Dissertação de mestrado em História. Niterói: UFF, 2012.

O EMPREITEIRO. Edição de outubro de 1972, nº 57.

O EMPREITEIRO. Edição de outubro de 1974, nº 81.

O EMPREITEIRO. Edição de abril de 1975, n 87.

O EMPREITEIRO. Edição de setembro de 1976, n 104.

O EMPREITEIRO. Edição de abril de 1977, n 111.

O EMPREITEIRO. Edição de junho de 1979, n 137.

O EMPREITEIRO. Edição de abril de 1980, n 147.

O EMPREITEIRO. Edição de março de 1984, n 196.

O EMPREITEIRO. Edição de setembro de 1984, n 202.

O GLOBO. Série 'Vidas em Blocos'. Edição de 11 de maio de 2011.

PAULA, Dilma Andrade de. A Cidade Submersa: o processo de destruição de São João Marcos, 1930-1945. Dissertação de mestrado em História. Rio de Janeiro: UFRJ, 1994.

PESTANA, Marco Marques. Ampliação seletiva do Estado e remoções de favelas no Rio de Janeiro (1957-1973): embates entre empresariado do setor imobiliário e movimento dos favelados. Tese de doutorado em História. Niterói: UFF, 2018.

PINTO, Lúcio Flávio. Tucuruí: a barragem da ditadura. Belém: Edição do autor, 2010.

QUINTELLA, Wilson. Memórias do Brasil Grande: a história das maiores obras do país dos homens que as fizeram. São Paulo: Saraiva / Vigília, 2008.

ROTSTEIN, Jaime. Em Defesa da Engenharia Brasileira. Rio de Janeiro: Engenharia, 1966.

SINICON. Dois Brasis: o que a infraestrutura está mudando. Cotia: Eolis Produções Culturais, 2009. 